\title{
LA ADAPTACIÓN DE LA ESTADÍSTICA EN EL CAMPO CENSAL: PROBLEMAS Y SOLUCIONES
}

\section{THE ADAPTATION OF STATISTICS IN THE FIELD OF CENSUS: PROBLEMS AND SOLUTIONS}

José Riquelme López: Asociación de Víctimas de Talidomida y otras Inhabilidades de España.

jose.riquelme@ozu.es

\section{CURRÍCULUM VITAE}

Presidente de la Asociación de Víctimas de Talidomida y otras Inhabilidades de España (AVITE). Destaca por su labor de lucha por el reconocimiento de los afectados por dicha droga a nivel nacional e internacional.

\section{RESUMEN}

El Instituto Nacional de Estadística en nuestro país carece de una base de datos nacional, a diferencia de otros países de Europa o el mundo. Por lo tanto, los Ayuntamientos no están intercomunicados entre sí. Los cambios en los Padrones de Habitantes tardan varios meses en realizarse y eso provoca multitud de problemas. Pero también hay soluciones. Eso se intenta exponer en este artículo.

\section{PALABRAS CLAVE}

INE - Censo - Habitantes 


\section{ABSTRACT}

The National Statistics Institute in our country lacks a national database, unlike other European country or the world. Therefore, the municipalities are not interconnected with each other. Changes in Population Patterns take several months to complete and that causes many problems. But there are solutions. That attempting to express in this article.

\section{KEY WORDS}

INE - Census - Population

\section{ÍNDICE}

1. Introducción

2. Lista de errores

3. Censo promocional

4. La herencia de un censo impertinente

TEXTO:

\section{Introducción}

El Instituto Nacional de Estadística (INE), hermano casi gemelo del esperpéntico y recordado INI, cree que todo el monte es orégano. La mayoría de Ayuntamientos de España, y concretamente sus departamentos de Estadística y Padrón de Habitantes, algunos municipios denominados "servicios al Estado"-, se ven cada día abocados a 
la sumisión ante este organismo estatal. El INE, desde su creación, campa a su aire, sin que nadie ponga coto a sus desmanes.

Nuestro país carece de una base de datos nacional, como sí ocurre, desde hace muchas décadas, en otros países europeos como Francia... En estos países, por poner un ejemplo, cuando se celebran comicios electorales, los electores ejercen su derecho al voto, con una simple tarjeta magnética, -como las de crédito o de la Seguridad Social- desde cualquier punto de su territorio. Pero como siempre, en este tema también vamos a remolque de Europa y de otros países del mundo.

Se echa en falta esa base de datos nacional, para que cualquier alta, baja, cambio de domicilio o modificación en los Padrones de Habitantes, fuese instantánea y simultánea, tanto en los Padrones Municipales, como en el Censo Electoral. Hoy día, con Internet, es más posible que nunca y posibilitaría lo que los Ayuntamientos demandan desde hace décadas: El estar intercomunicados e interconectados entre sí. Quizás puedan existir miedos y fantasmas políticos.

Pero no. Es más "fácil" para ellos llevar Censos Electorales, Censos de Población y Padrones de Habitantes en paralelo. Por un lado, los Padrones de Habitantes que gestionan cada uno de los Ayuntamientos. Luego el Censo Electoral y el de Población que mueve el INE; y que al final todos ellos, resultan un híbrido; porque todos ellos obran en poder del citado organismo, incluido los de Habitantes de todos los Ayuntamientos.

Todo ello trae consigo, y basta recordar algunos comicios electorales pasados, los cientos de miles de errores y omisiones que se producen. 


\section{Lista de errores}

El INE lo llama así, aunque son simple y llanamente incongruencias entre los Ayuntamientos y el Instituto.

Hasta hace unos años -coincidiendo con el reformado reglamento de Población y Demarcación de las Entidades Locales-, los ciudadanos, cuando se cambiaban de municipio o de ciudad, eran ellos mismos los que solicitaban su baja padronal y la presentaban en el respectivo Ayuntamiento, donde pretendían empadronarse, para así evitar duplicidades. Esto fue derogado por el INE, con una realidad encubierta: evitar "molestias" a los ciudadanos, para así, cuando una persona pretende empadronarse en un municipio, no precisa presentar su baja padronal, basta con presentarse en el Ayuntamiento en que quiere causar alta, y decir, de palabra y de viva voz, en que municipio figura empadronado, para que el nuevo ayuntamiento le solicite, a su vez, la baja.

Todo va encadenado y aquí es donde radica uno de los principales desmanes del INE. En la práctica la realidad diaria es muy distinta a la que, en un principio, pensaron. Pero tercos de ellos, siguen sin darse cuenta del caos que se ha organizado. O no quieren darse cuenta.

Estos ciudadanos, cuando causan alta en el nuevo municipio, bien por ignorancia, por desconocimiento, por indiferencia, por intereses hipotecarios por compra de vivienda o por picaresca, no informan con exactitud del nombre verdadero del municipio en donde realmente están empadronados. Por esta razón, la población en nuestro país, se está inflando de una manera vertiginosa, alarmante y desorbitada, duplicándose, triplicándose, cuadruplicándose... Y esto no hay quien lo pare. 
Pero a nadie parece importarle. De pronto el INE se saca de la manga lo que llaman, mal llaman, "lista de errores", que en realidad son incongruencias con los Ayuntamientos, principalmente por el motivo expuesto anteriormente. Pretender con esta lista solventar estos duplicados, nacimientos y defunciones mal incorporados, etc. es absurdo. Lo que realmente han conseguido es fomentar el caos en todos los Ayuntamientos de España, aparte de un enfrentamiento verbal entre el INE y los departamentos de Padrón de toda España. Motivado porque el primero de octubre tenían que estar resueltos los miles de errores e incongruencias que el INE les había comunicado a cada uno de los Ayuntamientos para éstos los "arreglasen" en sus padrones de una forma mágica y magistral.

Con esta "solución", pretendían tener al día los padrones continuos. Suprimieron las renovaciones padronales quinquenales que realizaban los Ayuntamientos. Y precisamente, en mayo del 2001, tenía que confeccionarse el Censo de Población y Vivienda. Pero era tal el caos, el desorden y la desorganización reinante organizada, que retrasaron la salida de los agentes censales a la calle en toda España, para octubre del 2001.

Para colmo de males, en este país no existen cifras oficiales de población, desde el primero de enero de 1998, aprobadas. Este retraso es debido a todas estas incompetencias manifiestas. En definitiva, no conocemos los habitantes que somos en este país desde enero del 98.

El descaro y la incompetencia de las cabezas pensantes del INE es tal, que salieron a la calle a recoger los datos Censales del Censo de Población y Vivienda en noviembre de 2001, con hojas preimpresas, recogidas de los Padrones de los Ayuntamientos, con una diferencia de 7 meses, entre la impresión de la hoja y la salida a la calle.

Pero el INE, que es mucho INE, no se conforma con ello. 


\section{Censo promocional}

Además de todo esto, y acogiéndose a la reformada LORTA, utilizando el Censo Electoral vigente, van a confeccionar el denominado Censo Promocional. Por supuesto también, con el apoyo de nuestro Parlamento.

Esto no es otra cosa que un Censo paralelo, sacado del Censo Electoral, que el INE proporcionará -¿venderá?- a todas aquellas empresas privadas que así se lo soliciten, para realizar mailis, enviar catálogos, venta de productos, televenta, etc...

En principio, todas las personas estaremos incluidas en este Censo Promocional, salvo si no deseamos aparecer en él o que nos quiten del mismo -como siempre, a la contra- tendremos que dirigirnos por carta, y solicitarlo expresamente al INE-. Y, por supuesto, siempre con el beneplácito de la Agencia de Protección de Datos Personales, organismo creado por el Gobierno, para defender no se sabe muy bien todavía a quien.

Y ni que decir tiene que, para las campañas electorales, también cede nuestros datos personales a todos aquellos partidos políticos que así se lo solicitan, para que el candidato de turno pueda dirigirnos, a nuestros domicilios, cartas personales propagandísticas de la campaña electoral e informarnos de lo mucho que piensan hacer, si llegan al poder. Amén de que desconocemos del uso posterior que dichos partidos políticos puedan hacer de esos nuestros datos de carácter personal.

El INE sigue teniendo un gran poder para manejar nuestros datos a su antojo y libre albedrío, y encima con la posibilidad de salir elegido miembros del Jurado Popular, que también son sacados del Censo Electoral. Además por su manifiesta incompetencia, el INE, tiene en España ¡4.000.000 de duplicados!, y no sabe qué hacer 
con ellos, ni cómo quitárselos de encima. De ahí el invento y la panacea utópica de la Cola de Errores.

Mientras potencien sus SAC, (Servicios de Atención al Ciudadano), en el que engloban diversos negociados, por el bien de los ciudadanos propiamente dichos, incluidos los Padrones Municipales de Habitantes, los Ayuntamientos, se verán impotentes de mantener al día la Cola de Errores del INE, por simple lógica y sentido común.

\section{La herencia de un censo impertinente}

Molina de Segura, tenía, en septiembre del 2001, 48.500 habitantes. Después del Censo de Población que ha llevado a cabo el ínclito INE, ha perdido 9.000 habitantes. Madrid, Barcelona... y así todos los ayuntamientos de España. Con ello, se ha perdido una población aproximada de un 20 \% en el país.

El INE salió a la calle a realizar el Censo, con hojas pre-impresas, con los datos de los habitantes que los Ayuntamientos les habían facilitado y que constaban en sus padrones, excepto en el País Vasco, que se negaron a realizar este censo y no pasó absolutamente nada.

Después del tiempo y el costo que el INE ha dedicado a ello, contratando agentes censales, ahora los Ayuntamientos tienen la ardua labor de intentar localizar a todas esas personas que el INE ha "perdido", contratando nuevos agentes censales, si sus presupuestos se lo permiten o buscándose la vida.

Si los Ayuntamientos no encuentran a estas personas desaparecidas, el INE tiene plena potestad para darlos de baja en el Censo Electoral -de hecho, las personas que no han localizado, ya son propuestas de baja-, por lo que de nuevo el casos y la 
debacle está asegurada en los próximos comicios electorales: las elecciones generales y Parlamento Europeo y por extensión, el trastorno que va a causar a los Ayuntamientos es mayúsculo, debido a la gran cantidad de bajas que de un plumazo se van a dar a cientos de personas, sin haber tenido ni arte ni parte los Ayuntamientos.

Nota: ¡6 meses después de acabar su trabajo en los censos de población y viviendas del 2001, los agentes censales y otros colaboradores del censo de población y vivienda, el INE todavía les adeudaba dinero! 